\title{
Editorial Special Issue on EUROMOD
}

\author{
Francesco Figari - Guest Editor \\ University of Insubria and ISER, University of Essex \\ Via M.te Generoso 71, 21100 Varese (IT); \\ e-mail: francesco.figari@uninsubria.it \\ Iva Valentinova Tasseva - Guest Editor \\ Institute for Social and Economic Research, University of Essex \\ Wivenhoe Park, CO3 4SQ Colchester (UK); \\ e-mail: itasseva@essex.ac.uk
}

The spring special issue of the International Journal of Microsimulation celebrates the launch of the new release of EUROMOD, the European Union tax-benefit microsimulation model. For the first time, EUROMOD covers all 27 countries of the European Union and represents a remarkable achievement for the microsimulation research community, being the result of more than 15 years of accumulated expertise.

The papers included in the special issue were presented at the $2^{\text {nd }}$ Microsimulation Research Workshop in October 2012, organized by the Institute for Social and Economic Research (University of Essex) and hosted by the National Research Institute for Labour and Social Protection in Bucharest, Romania. Research findings based for the first time on EUROMOD covering all 27 European Member States are presented. Furthermore, the issue looks at the importance and implications of choosing a certain input data for microsimulation and at the solutions of different data issues. Finally, analysis on the redistributive policy effects and work incentives is presented based on EUROMOD spin-off models for Russia and Serbia.

In the first paper of this issue, Francesco Figari and Holly Sutherland provide an introduction to the current state of the art of EUROMOD and its development. The EU wide coverage, its user friendliness and the open accessibility make of EUROMOD a valuable research infrastructure at the disposal of academics and policy makers, as shown by its recent applications reviewed in the 
paper. The plans to overcome the current limitations and further developments pose some important challenges and show the vitality of the EUROMOD community.

It is expected that EUROMOD for the whole EU-27 countries will be increasingly used at national and European level in the near future. The first two applications appear in this issue.

H. Xavier Jara and Alberto Tumino analyse the impact of tax-benefit systems on income inequality and work incentives across the 27 Member States of the European Union. The extent to which tax-benefit systems contribute to income redistribution and provide work incentives is found to vary considerably across Europe, and the equity-efficiency trade-off is confirmed by looking at the effects of policy changes between 2007 and 2010.

Horacio Levy, Manos Matsaganis and Holly Sutherland study the within and between country distributional implications of an illustrative Child Basic Income operated and partly funded at EU level. They estimate the cost of such scheme, its impact on poverty among the children targeted by the scheme, and the fiscal flows between Member States. The paper shows the great potential of EUROMOD to analyse the impact of potential EU wide policies, in particular of those aimed to strengthen solidarity across national boundaries in the EU.

As part of the EUROMOD development, an increasing attention is devoted to ensuring the transparency of the assumptions and the availability of validation assessments (see, for example, EUROMOD Country Reports available at the EUROMOD web site) in order to ensure the credibility of the results of the applications based on EUROMOD. One of the key ingredients in this process is the reliability of the input data as shown by Lidia Ceriani, Carlo V. Fiorio and Chiara Gigliarano. They explore the pros and cons of alternative data sets for static tax-benefit microsimulation in Italy. In their analysis, they highlight the importance of the treatment of tax evasion and matching of different input data, which can improve the quality of the simulations with lessons that can be useful for other countries as well.

The availability of using EUROMOD framework in order to build static tax-benefit microsimulation models for non-EU countries has made possible the development of a number of spin-off models, which have appeared recently and have confirmed the great value of knowledge transfer from the EUROMOD community to other users.

In this issue, the models for Russia (RUSMOD) and Serbia (SRMOD) are presented along with two recent applications of potential policy reforms. 
The paper by Daria Popova provides an analysis of alternative scenarios for improving the design of Child Allowances in Russia. The benefit, at the focus of the paper, has a poor targeting performance and varies across regions of Russia in terms of design and generosity, which raises serious equity concerns. Redirecting these resources to the poor - by means of better targeting, increasing generosity and implementing a unified national design - enhances the effects on child poverty even at the current level of spending.

The final paper by Saša Ranđelović and Jelena Žarković Rakić provides empirical evidence on the impact of the abolishment of the mandatory minimum Social Security Contribution base on the work incentives and income distribution in Serbia. The suggested policy reform would increase the work incentives, in particular, for the lower income groups with some positive distributional effects.

Finally, on behalf of the Editor, Gijs Dekkers, we would like to point out that the template of the International Journal of Microsimulation has gone through considerable changes in order to coincide with the new layout of the IJM web site and to provide an improved and more readable style. 